\title{
ZD6474 - clinical experience to date
}

\author{
JV Heymach*,I \\ 'Lowe Center for Thoracic Oncology, Dana Farber Cancer Institute, 44 Binney St, Boston, MA 02 I I5, USA
}

\begin{abstract}
ZD6474 selectively targets two key pathways in tumour growth by inhibiting vascular endothelial growth factor (VEGF)-dependent tumour angiogenesis and epidermal growth factor (EGF)-dependent tumour cell proliferation and survival. Phase I clinical evaluation has shown ZD6474 to be generally well tolerated, with a pharmacokinetic profile appropriate for once-daily oral dosing. Phase II evaluation of ZD6474 at doses of 100-300 mg is ongoing in a range of patient types in single and combination regimens. These include three randomised studies of patients with non-small-cell lung cancer. In one of these trials, the efficacy of ZD6474 monotherapy is being compared with that of the EGF receptor tyrosine kinase inhibitor gefitinib (Iressa ${ }^{\mathrm{TM}}$ ) in previously treated patients. In the other two trials, the efficacy of ZD6474 in combination with certain standard chemotherapy regimens is being compared with that of standard chemotherapy alone: one with carboplatin and paclitaxel in previously untreated patients, and the second with docetaxel in patients who progressed after platinum-containing therapy. The advent of novel molecular-targeted agents such as ZD6474 has necessitated a re-evaluation of conventional cancer study design in order to optimise appraisal of this new generation of anticancer agents. The specific considerations of the ZD6474 clinical programme are discussed.
\end{abstract} British Journal of Cancer (2005) 92(SuppI I), SI4-S20. doi:I0.I038/sj.bjc.6602604 www.bjcancer.com (c) 2005 Cancer Research UK

Keywords: ZD6474; antitumour; VEGFR inhibitor; EGFR inhibitor; non-small-cell lung cancer

It is generally accepted that significant advances in cancer treatment will require the identification of novel targets critical for cancer growth and progression, and the development of strategies to inhibit these targets. Two promising targets are the vascular endothelial growth factor (VEGF) pathway, which is a key mediator of tumour angiogenesis, and the epidermal growth factor receptor (EGFR). The therapeutic value of inhibiting these targets has been demonstrated by the anti-VEGF monoclonal antibody, bevacizumab (Avastin ${ }^{\mathrm{TM}}$ ), the anti-EGFR monoclonal antibody cetuximab (Erbitux ${ }^{\mathrm{TM}}$ ) and the EGFR tyrosine kinase inhibitors erlotinib (Tarceva ${ }^{\mathrm{TM}}$ ) and gefitinib (Iressa ${ }^{\mathrm{TM}}$ ) (Fukuoka et al, 2003; Cunningham et al, 2004; Hurwitz et al, 2004; Shepherd et al, 2004).

ZD6474 is an oral, small molecule inhibitor of VEGFR and EGFR tyrosine kinase activity. By targeting these two pathways, ZD6474 has the potential to offer the combined benefits of directly inhibiting tumour cell proliferation and survival like other EGFR inhibitors, as well as inhibiting tumour angiogenesis by inhibiting VEGF activity. In addition, EGFR inhibitors have themselves been shown to exert antiangiogenic effects by reducing the expression of VEGF and other angiogenic factors by tumours (Ciardiello et al, 2001), and inhibiting EGFR on tumour endothelium (Bruns et al, 2000; Baker et al, 2002). Combined blockade of the VEGF and EGFR pathways may therefore provide greater benefit than blockade of either pathway alone. Although clinical experience with combined VEGF/EGFR inhibition is limited, in a recent phase I/II trial of patients with previously treated non-small-cell lung cancer (NSCLC; nonsquamous histology) the combination of

\footnotetext{
*Correspondence: Dr JV Heymach;
}

E-mail: John_Heymach@dfci.harvard.edu erlotinib and bevacizumab showed encouraging antitumour activity (Herbst et al, 2005).

\section{ZD6474 CLINICAL EVALUATION: CONSIDERATIONS IN TRIAL DESIGN}

Clinical evaluation of the new generation of molecular-targeted therapies has presented a number of challenges, not least of which is how to design clinical trials that effectively identify the potential of these novel agents. The format of a typical cancer study has developed over many years to evaluate cytotoxic chemotherapy regimens, where tumour regression is the expected outcome for an active agent. In contrast, antiangiogenic agents, like many other types of targeted drugs, are more likely to elicit a cytostatic effect, rather than tumour shrinkage. In addition, while cytotoxic agents are typically used at doses at or near the maximum tolerated dose (MTD), the optimal dose for targeted agents may be at doses far below the MTD. Evaluation of these agents will therefore require refinements in trial design to robustly detect 'soft' end points such as stable disease, coupled with the development and validation of improved markers for assessing biological activity.

The principal objective of initial clinical evaluation of ZD6474 was to determine safety and tolerability of this agent, and is discussed below. This followed a conventional format and, as is typical for phase I testing, involved patients with advanced, refractory tumours of various types. The inclusion of a 7-day observation period following initial dosing in these studies also enabled assessment of both single- and multiple-dose effects within the same study. Evidence of tumour responses to ZD6474 therapy seen in the phase I programme and the known activity of EGFR inhibitors in NSCLC prompted a comprehensive phase II 
evaluation in this tumour type. The main objective of the phase II evaluation of ZD6474 in NSCLC is the assessment of time-totumour progression, which is considered the best description of clinical effect of the antiangiogenic agents. Assessment of tumour response is also included as a secondary end point to capture any frank responses to therapy.

Although phase II studies tend not to include a control arm and aim to enrol the minimum number of patients, the use of randomised trials has recently been recommended for screening promising new agents, especially those expected to be cytostatic (Korn et al, 2001; Simon et al, 2001). In such trials, a one-sided $P$-value of less than 0.2 is considered evidence that the new agent shows sufficient promise to warrant further investigation, that is, a $P$-value of $<0.2$ would indicate that there was a less than 1 in 5 probability that the observed increase in activity was due to chance alone. A randomised trial design has been adopted for the phase II evaluation of ZD6474 in NSCLC in order to provide more meaningful outcomes than single-arm studies and avoid the necessity for comparison with historical data. The combination studies include a safety run-in phase designed to evaluate the tolerability profile of the combination and to allow early identification of any pharmacokinetic interactions prior to the main randomised phase. Collection of a wealth of additional data is also included in these protocols, including health-related quality of life assessments using the Functional Assessment of Cancer Therapy-Lung (FACT-L) questionnaire and lung cancer subscore. This will provide useful information for determining appropriate outcome end points for future studies.

\section{PHASE I CLINICAL EVALUATION}

ZD6474 has been evaluated in two phase I clinical trials of patients with advanced solid tumours refractory to standard therapy (Figure 1). The primary objective of both studies was to evaluate the safety and tolerability of ascending doses of ZD6474. Secondary objectives included assessment of the pharmacokinetic profile of ZD6474, determination of the MTD and preliminary assessment of ZD6474 antitumour activity.

Study A recruited 77 patients from five sites in the USA and Australia (Hurwitz et al, 2002). Patients with a variety of solid tumours were included, most having colorectal cancer (CRC) $(n=23)$, but only one had NSCLC. Patients received daily oral ZD6474 at doses of 50,100,200,300,500 or $600 \mathrm{mg}$ in 28-day cycles. Preliminary data from 49 patients shows that good tolerability at doses as high as $500 \mathrm{mg}$ and dosing for $>100$ days has been achieved. Expanded cohorts of 8-10 patients were also evaluated sequentially at 100 and $300 \mathrm{mg}$ dose levels in order to further characterise the safety, tolerability and biological activity of ZD6474. The incidence of rash and diarrhoea appeared to be dose- related and asymptomatic QTc prolongation was observed in seven patients at varying dose levels. The observation of three CTC grade 3 events in patients receiving $600 \mathrm{mg}$ ZD6474 (two episodes of diarrhoea and one of thrombocytopenia) indicated that this dose level exceeded the MTD and no further dose escalation was performed. ZD6474 exposure ( $C_{\max }$, AUC) following single-dose administration increased with dose. The $t_{1 / 2}$ was long $(>100 \mathrm{~h}$ ) and did not change with increasing dose. The anti-VEGF activity of ZD6474 was suggested by the occurrence of hypertension and delayed dermal wound angiogenesis, although no tumour responses were seen in this study.

Study B recruited 18 patients in Japan, most of whom had NSCLC or CRC ( $n=9$ and 4 , respectively). Patients received ZD6474 at doses of $100,200,300$ or $400 \mathrm{mg}$ in 28-day cycles. In this study, ZD6474 therapy was well tolerated at doses of up to $300 \mathrm{mg} \mathrm{day}^{-1}$, the most common adverse events being rash, asymptomatic QTc prolongation, diarrhoea, proteinuria and hypertension. Two patients developed a DLT (grade 3 ALT elevation and grade 3 hypertension) at $400 \mathrm{mg} \mathrm{day}^{-1}$, which was considered to exceed the MTD. According to RECIST criteria, four of the nine patients with NSCLC exhibited an objective response to ZD6474 therapy. Two of the observed tumour responses are shown in Figure 2, both patients received dose reductions (300-200 and 200-100 $\mathrm{mg} \mathrm{day}^{-1}$ ) following an adverse event. It is not known whether these patients had EGFR mutations characteristic of NSCLC patients that are highly responsive to EGFR inhibitors (Lynch et al, 2004; Paez et al, 2004). In preclinical studies, EGFR mutations known to increase the sensitivity of EGFR to gefitinib and erlotinib also increased sensitivity to ZD6474 (Arao et al, 2004; Briggs et al, 2005).

In summary, phase I evaluation of ZD6474 has shown this novel agent to be well tolerated at daily oral doses of $\leqslant 300 \mathrm{mg}$. Observed adverse events were generally mild and readily controlled with dose adjustment or appropriate therapy; all QTc prolongation events were asymptomatic. The pharmacokinetic profile of ZD6474 was compatible with once-daily oral dosing and did not differ between the Western and Japanese studies. This, along with the encouraging tumour response data, has prompted initiation of a comprehensive series of phase II clinical evaluations.

\section{PHASE II CLINICAL EVALUATION OF ZD6474}

Phase II assessment of ZD6474 is now underway in a variety of tumour types in single and combination regimens. ZD6474 doses of $100-300 \mathrm{mg} \mathrm{day}^{-1}$ were selected for the phase II studies, as these doses are known to be well tolerated and pharmacokinetic data from phase I evaluation indicate that even the $100 \mathrm{mg}$ dose is expected to yield biologically active systemic concentrations of ZD6474.

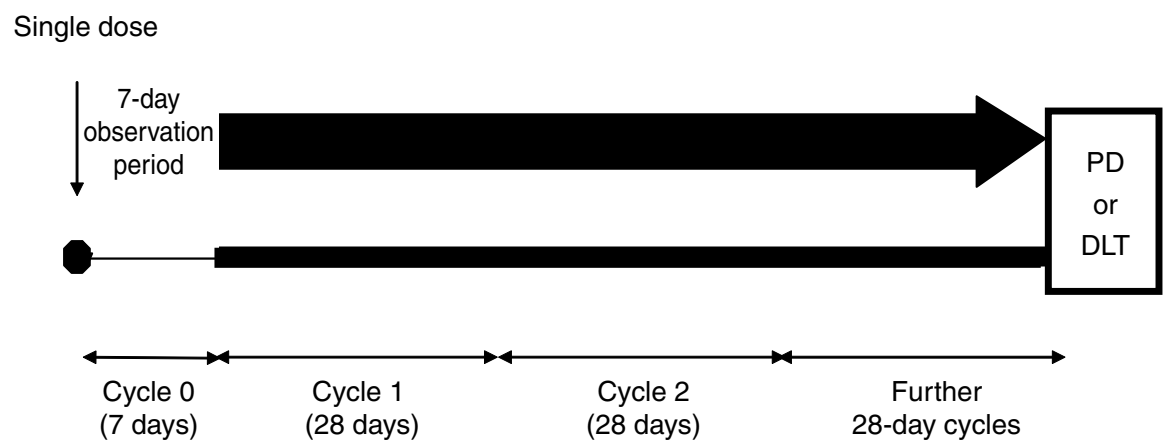

$\mathrm{PD}=$ progressive disease; $\mathrm{DLT}=$ dose-limiting toxicity

Figure I Phase I study design. ZD6474 dosed once-daily p.o. Study A 50-600 mg; study B $100-400$ mg. 


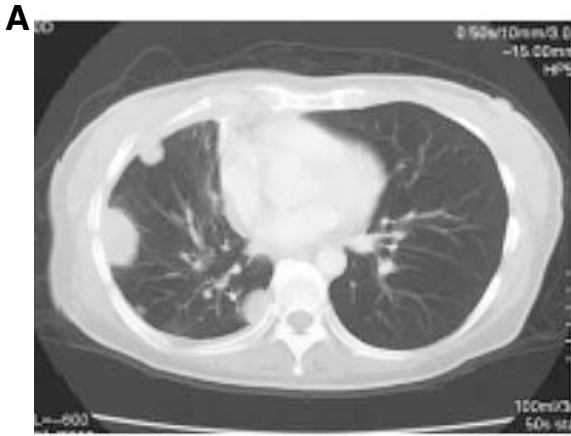

Predose

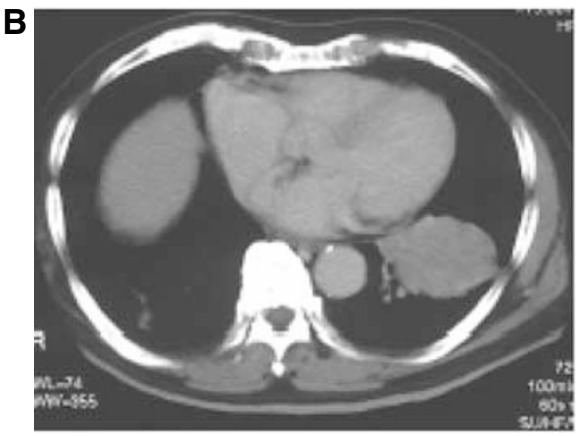

Predose

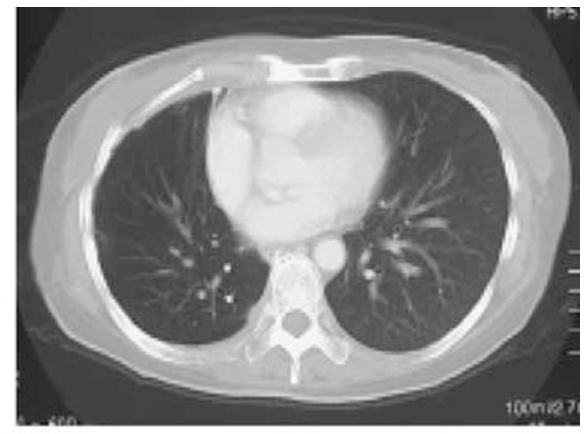

Withdrawal (cycle 5, day 9)

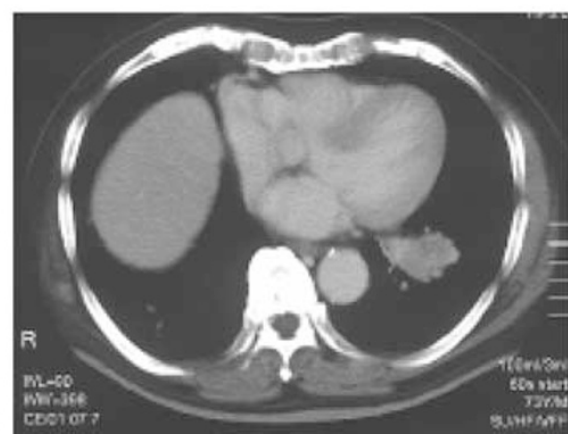

Withdrawal (cycle 7, day 29)

Figure 2 Tumour responses observed in phase I study of ZD6474. (A) Female, 50 years, receiving ZD6474 $300 \rightarrow 200 \mathrm{mg}$ day ${ }^{-1}$; $(\mathbf{B})$ male, 72 years, receiving ZD6474 $200 \rightarrow 100$ mg day $^{-1}$.

\section{NON-SMALL-CELL LUNG CANCER STUDIES}

Although the activity of ZD6474 is being assessed in a range of tumour types, the responses to ZD6474 in patients with NSCLC seen in phase I study B have prompted a series of studies in this tumour type. Current standard therapy for NSCLC has only limited efficacy and although a minority of patients do respond to treatment, the majority of responders will eventually develop progressive disease (Schiller et al, 2002). The prognosis for patients with this tumour type therefore remains poor and there is a high unmet need for new therapies.

As with all solid tumours, the role of angiogenesis is well established in the progression of lung cancers, and high microvessel density has been shown to be predictive of tumour progression, metastasis and therefore poor prognosis (Macchiarini et al, 1992, 1994; Fontanini et al, 1997; Lucchi et al, 1997; Meert et al, 2002). It is therefore possible that inhibition of VEGF activity and thereby angiogenesis could have significant therapeutic benefits in patients with NSCLC.

\section{ZD6474 VS GEFITINIB IN PREVIOUSLY TREATED NSCLC}

Gefitinib is a small molecule inhibitor of the EGFR tyrosine kinase that has demonstrated significant antitumour efficacy in patients with previously treated NSCLC (Fukuoka et al, 2003). In order to determine the additional benefit of VEGFR tyrosine kinase inhibition, a comparative study of ZD6474 and gefitinib has been initiated in subjects with locally advanced or metastatic (IIIB/IV) NSCLC after failure of either first-line and/or second-line platinum-based chemotherapy. The crossover design (Figure 3) also allows assessment of the activity of ZD6474 in subjects who have failed treatment with gefitinib. In part $A$, patients receive daily oral doses of either ZD6474 $300 \mathrm{mg}$ or gefitinib $250 \mathrm{mg}$. The ZD6474 dose selection was based on extrapolations from in vitro studies, which demonstrated that the $300 \mathrm{mg}$ dose of ZD6474 could be expected to provide approximately equivalent inhibition of the EGFR tyrosine kinase as gefitinib $250 \mathrm{mg}$. Treatment continues until withdrawal due to disease progression, toxicity or removal of informed consent. After a washout period of 4 weeks, patients are switched to the alternative treatment (part B), which continues until a withdrawal criterion is reached. In both parts of this study, the dual primary objective is evaluation of time to progression and assessment of safety/tolerability. The initial phase of this study is now complete and the results are anticipated shortly.

\section{ZD6474 PLUS DOCETAXEL}

Docetaxel is currently a standard chemotherapy agent for previously treated patients with NSCLC. In randomised phase III studies, the overall response rate has ranged from 6 to $9 \%$, with a median progression-free survival of 8.5-12.6 weeks (Shepherd et al, 2000; Fossella et al, 2000; Hanna et al, 2004). Docetaxel has also been found to act synergistically with VEGF pathway inhibitors in preclinical studies (Sweeney et al, 2001).

The potential for improved therapeutic efficacy in combination with ZD6474 is being investigated in a two-part randomised, double-blind, placebo-controlled trial (Figure 4). Patients with locally advanced or metastatic NSCLC after failure of first-line platinum-based chemotherapy were recruited and initially received docetaxel $\left(75 \mathrm{mg} \mathrm{m}^{-2}\right.$ i.v. infusion every 21 days) plus daily oral ZD6474 (100 or $300 \mathrm{mg}$ ) in the open-label safety run-in phase. In the subsequent randomised phase, a docetaxel/placebo group was included. The primary objective of this study is to compare progression-free survival, as determined by objective tumour assessments (revised RECIST).

A randomised study, rather than a single-arm protocol, was performed as the activity of docetaxel observed to date in secondline NSCLC trials has been highly variable, making comparison 
Part A

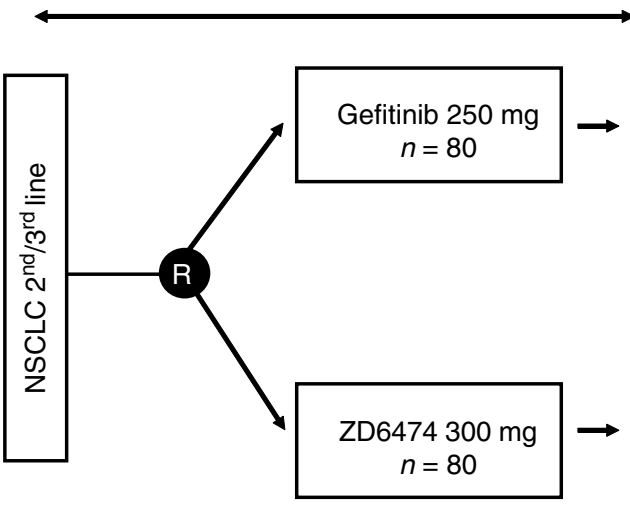

Part B

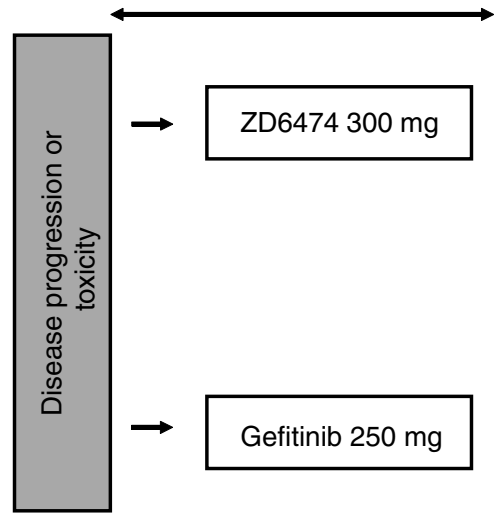

Figure 3 Gefitinib compared with ZD6474; switch-over study design.

Run-in phase

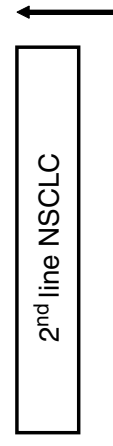

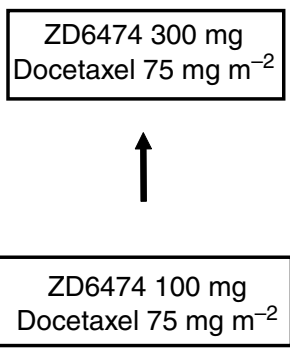

Randomised phase

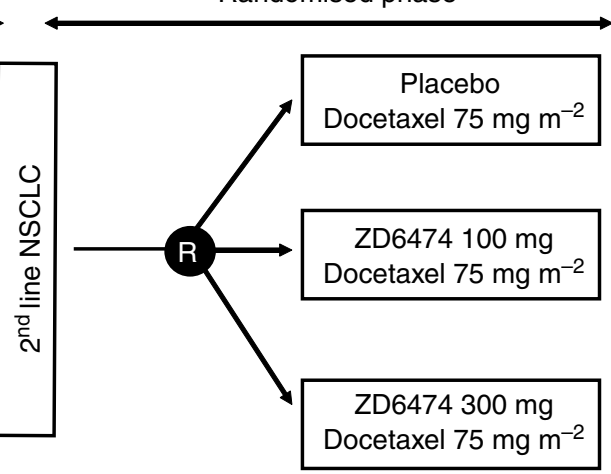

Figure 4 ZD6474/docetaxel combination study design.

with historical data difficult. In addition, the inclusion of a control arm allows the tolerability profile of the combination arms to be rigorously placed into context with that observed for docetaxel alone.

Preliminary data from the run-in phase of this study have demonstrated that the combination of ZD6474 and docetaxel does not significantly increase the toxicity or exposure of either agent (Heymach et al, 2004). The combination was generally well tolerated and adverse events were manageable. Approximately half of the patients exhibited stable disease $\geqslant 12$ weeks and two partial responses were seen in the ZD6474 $300 \mathrm{mg}$ cohort (Figure 5). Overall median time to disease progression was 15.1 and 19.8 weeks in the ZD6474 100 and $300 \mathrm{mg}$ cohorts, respectively. There was a higher incidence of rash in the $300 \mathrm{mg}$ cohort, possibly due in part to a higher degree of EGFR inhibition. These data therefore support progression to the double-blind, randomised phase, which has now completed accrual.

\section{ZD6474 PLUS CARBOPLATIN AND PACLITAXEL}

ZD6474 is being evaluated in an ongoing randomised, doubleblind phase II study, alone and in combination with carboplatin/ paclitaxel (CP), as first-line treatment for patients with locally advanced or metastatic (IIIB-IV) NSCLC (Figure 6). A safety runin phase was conducted to establish the appropriate dose of ZD6474 to be administered in combination with CP, and comprised 21-day treatment cycles in which 10 subjects per cohort received daily oral doses of ZD6474 (1st cohort, $200 \mathrm{mg}$; 2nd cohort, $300 \mathrm{mg}$ ) in combination with CP (carboplatin, target
$\mathrm{AUC}_{\mathrm{ss}}=6 \mathrm{mg} \mathrm{ml}^{-1} \mathrm{~min}$; paclitaxel, $200 \mathrm{mg} \mathrm{m}^{-2}$ i.v.). In the randomised phase, the inclusion of a control arm will allow the tolerability profile of the ZD6474/CP combination arm to accurately compare with that of $\mathrm{CP}$ only.

Preliminary data from the run-in phase of this study show that the ZD6474/CP combination is generally well tolerated (Johnson et al, 2005). Partial responses have been observed in seven out of 18 patients and stable disease $\geqslant 12$ weeks in a further two patients. Preliminary pharmacokinetic data indicate that mean steady-state plasma levels of ZD6474 after $200 \mathrm{mg}$ dosing are comparable when given alone $\left(684 \mathrm{ng} \mathrm{ml}^{-1} \pm 272\right)$ or in combination with $\mathrm{CP}$ $\left(568 \mathrm{ng} \mathrm{ml}^{-1} \pm 206\right)$. These preliminary results have supported progression to the randomised phase, which is currently ongoing.

It is worth noting that two previous phase III studies of CP combined with either gefitinib or erlotinib did not demonstrate improved survival compared with CP alone (Herbst et al, 2004a, b). When CP was combined with the VEGF inhibitor bevacizumab, however, promising activity was seen in terms of overall response rate and time to progression (Johnson et al, 2004). A phase III trial of this regimen (ECOG 4599) has now completed accrual. Given these results, it will be of particular interest to determine whether a dual VEGF/EGFR inhibitor will increase the effectiveness of CP chemotherapy for first-line NSCLC.

\section{CLINICAL EVALUATION OF ZD6474 IN OTHER TUMOUR TYPES}

ZD6474 as monotherapy has been evaluated in a phase II study of 46 patients with previously treated metastatic breast cancer. In this 


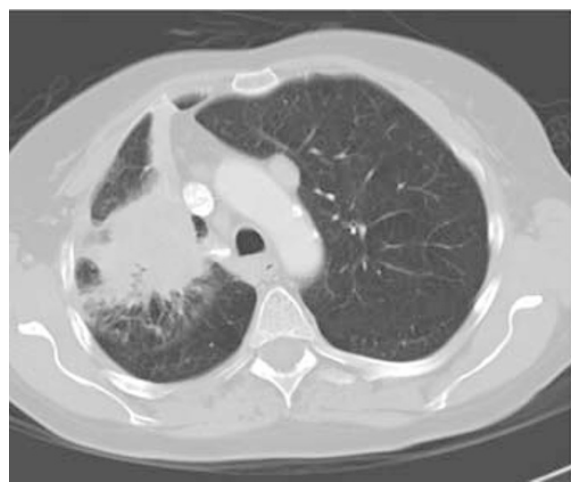

Pretreatment

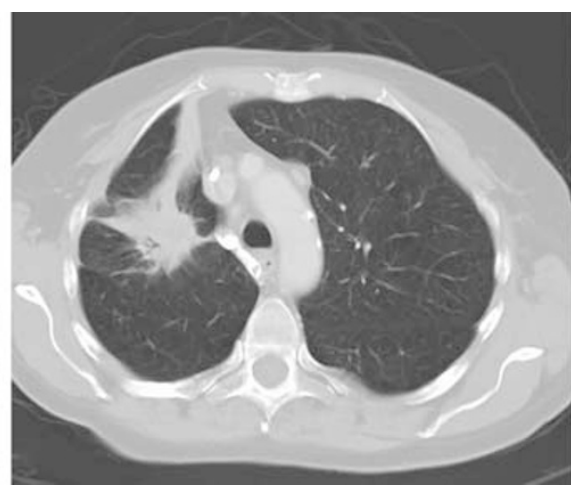

Post-treatment

Figure 5 Tumour response following two 21 -day cycles of ZD6474 (300 $\left.\mathrm{mg} \mathrm{day}^{-1}\right)$ plus docetaxel $\left(75 \mathrm{mg} \mathrm{m}^{-2}\right.$ every 21 days $)$ therapy.

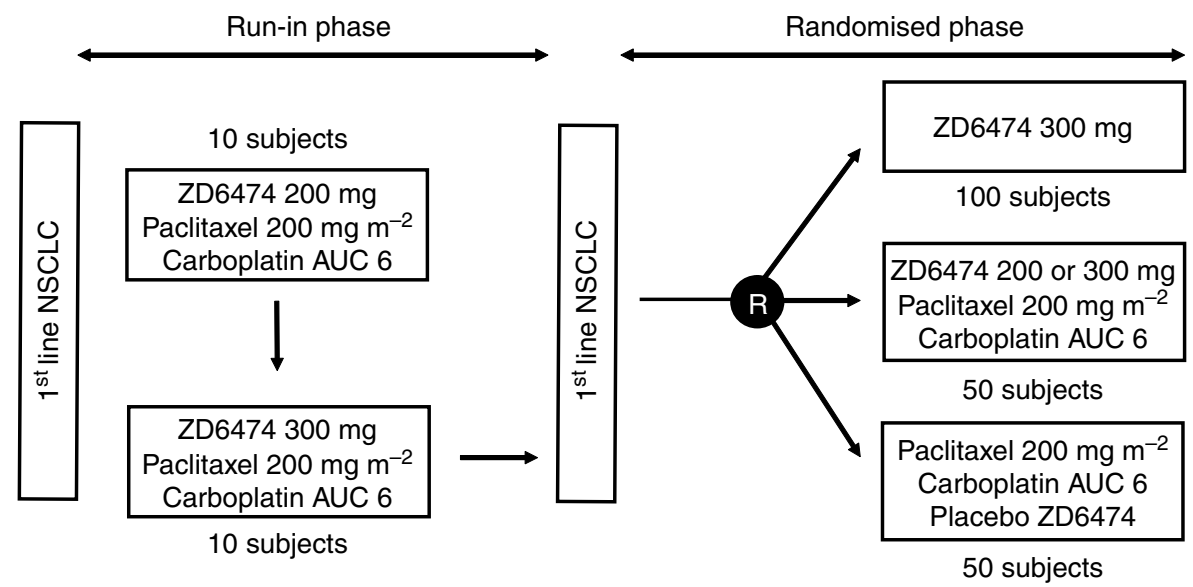

Figure 6 Design of carboplatin/paclitaxel/ZD6474 combination study in first-line NSCLC patients.

study, patients received once-daily ZD6474 therapy at a dose of 100 or $300 \mathrm{mg}$ (Miller et al, 2004). ZD6474 therapy was generally well tolerated, with mild diarrhoea and rash being the most commonly reported adverse events. There were no objective responses seen in this study. Phase I evaluation of bevacizumab in patients with advanced cancers, including breast cancer, also showed no responses (Gordon et al, 2001). A subsequent phase I/II dose escalation study in previously treated metastatic breast cancer patients has shown more promising results, with a confirmed response rate of $6.7 \%$ (Cobleigh et al, 2003).

It is possible that the lack of clinical benefit in the ZD6474 study may be due to the advanced, previously treated nature of the patient group. It is also possible that early-stage tumours have a greater reliance on VEGF as the principal proangiogenic factor, while in advanced tumours there may be a degree of redundancy, with angiogenesis being governed by a wider range of proangiogenic factors (Relf et al, 1997; Pavlakovic et al, 2001; Kerbel, 2004). Also, while EGF is an important mediator of normal mammary gland development and neoplastic transformation, the value of inhibiting EGF functioning in the treatment of breast cancer remains uncertain. Further research will elucidate whether certain tumour types are more or less susceptible to anti-VEGF/EGF strategies, and breast cancer may prove to be a tumour type that is difficult to treat with this approach.

Other studies of ZD6474 include small-cell lung cancer (SCLC) and multiple myeloma (MM). The ongoing SCLC study is recruiting patients who have experienced a complete or partial response to induction chemotherapy \pm radiation therapy. The primary objective is assessment of time to progression. In addition, a correlation between outcome or response and tumour VEGFR expression and microvascular density will be assessed. As $\mathrm{MM}$ is a disease in which angiogenesis is believed to be a relevant target for therapy, a phase II trial of ZD6474 $100 \mathrm{mg}$ p.o. daily in patients with relapsed MM has been conducted. Although ZD6474 therapy was well tolerated in this population, the primary efficacy end point, objective response as assessed by reduction in $M$ protein, was not achieved (Kovacs et al, 2004).

\section{CONCLUSIONS}

ZD6474 has the potential to exert both direct and indirect antitumour effects, via inhibition of VEGFR-2 and EGFR tyrosine kinase activity, respectively. Early clinical evaluation of this novel agent has demonstrated a promising efficacy and safety profile and the comprehensive series of ongoing phase II studies will clarify the value of this approach in the treatment of solid tumours. Our knowledge of tumour biology suggests that targeting multiple pathways in tumour growth and development will be critical, although early clinical experience indicates that there is still much to be learned about how to optimally combine these targeted agents with one another and with chemotherapy. Careful patient selection may be necessary in order to ensure targeted therapy is administered to those most likely to gain clinical benefit from this novel therapeutic approach. The identification of surrogate markers of treatment efficacy will be key to attaining this goal and is the subject of much ongoing research. 


\section{REFERENCES}

Arao T, Fukumoto H, Takeda M, Tamura T, Saijo N, Nishio K (2004) Small in-frame deletion in the epidermal growth factor receptor as a target for ZD6474. Cancer Res 64: 9101-9104

Baker CH, Solorzano CC, Fidler IJ (2002) Blockade of vascular endothelial growth factor receptor and epidermal growth factor receptor signaling for therapy of metastatic human pancreatic cancer. Cancer Res 62: 1996 2003

Briggs AD, Molofsky A, Wang J, Engelman P, Beaudry D, Prox D, Tracy S, Ryan AJ, Folkman J, Janne P, Johnson BE, Heymach JV (2005) Sensitivity of NSCLC cell lines bearing wild type and mutated EGFR to the VEGF/ EGFR inhibitor ZD6474. Proc Am Assoc Cancer Res 46: abstract 5833

Bruns CJ, Solorzano CC, Harbison MT, Ozawa S, Tsan R, Fan D, Abbruzzese J, Traxler P, Buchdunger E, Radinsky R, Fidler IJ (2000) Blockade of the epidermal growth factor receptor signaling by a novel tyrosine kinase inhibitor leads to apoptosis of endothelial cells and therapy of human pancreatic carcinoma. Cancer Res 60: 2926-2935

Ciardiello F, Caputo R, Bianco R, Damiano V, Fontanini G, Cuccato S, De Placido S, Bianco AR, Tortora G (2001) Inhibition of growth factor production and angiogenesis in human cancer cells by ZD1839 (Iressa), a selective epidermal growth factor receptor tyrosine kinase inhibitor. Clin Cancer Res 7: $1459-1465$

Cobleigh MA, Langmuir VK, Sledge GW, Miller KD, Haney L, Novotny WF, Reimann JD, Vassel A (2003) A phase I/II dose-escalation trial of bevacizumab in previously treated metastatic breast cancer. Semin Oncol 30: $117-124$

Cunningham D, Humblet Y, Siena S, Khayat D, Bleiberg H, Santoro A, Bets D, Mueser M, Harstrick A, Verslype C, Chau I, Van Cutsem E (2004) Cetuximab monotherapy and cetuximab plus irinotecan in irinotecanrefractory metastatic colorectal cancer. $N$ Engl J Med 351: 337-345

Fontanini G, Lucchi M, Vignati S, Mussi A, Ciardiello F, De Laurentiis M, De Placido S, Basolo F, Angeletti CA, Bevilacqua G (1997) Angiogenesis as a prognostic indicator of survival in non-small-cell lung carcinoma: a prospective study. J Natl Cancer Inst 89: 881-886

Fossella FV, DeVore R, Kerr RN, Crawford J, Natale RR, Dunphy F, Kalman L, Miller V, Lee JS, Moore M, Gandara D, Karp D, Vokes E, Kris M, Kim Y, Gamza F, Hammershaimb L (2000) Randomized phase III trial of docetaxel versus vinorelbine or ifosfamide in patients with advanced non-small-cell lung cancer previously treated with platinum-containing chemotherapy regimens. The TAX 320 Non-Small Cell Lung Cancer Study Group. J Clin Oncol 18: 2354-2362

Fukuoka M, Yano S, Giaccone G, Tamura T, Nakagawa K, Douillard JY, Nishiwaki Y, Vansteenkiste J, Kudoh S, Rischin D, Eek R, Horai T, Noda K, Takata I, Smit E, Averbuch S, Macleod A, Feyereislova A, Dong RP, Baselga J (2003) Multi-institutional randomized phase II trial of gefitinib for previously treated patients with advanced non-small-cell lung cancer. J Clin Oncol 21: 2237-2246

Gordon MS, Margolin K, Talpaz M, Sledge Jr GW, Holmgren E, Benjamin R, Stalter S, Shak S, Adelman D (2001) Phase I safety and pharmacokinetic study of recombinant human anti-vascular endothelial growth factor in patients with advanced cancer. J Clin Oncol 19: 843-850

Hanna N, Shepherd FA, Fossella FV, Pereira JR, De Marinis F, von Pawel J, Gatzemeier U, Tsao TC, Pless M, Muller T, Lim HL, Desch C, Szondy K, Gervais R, Shaharyar, Manegold C, Paul S, Paoletti P, Einhorn L, Bunn Jr PA (2004) Randomized phase III trial of pemetrexed versus docetaxel in patients with non-small-cell lung cancer previously treated with chemotherapy. J Clin Oncol 22: 1589-1597

Herbst RS, Giaccone G, Schiller JH, Natale RB, Miller V, Manegold C, Scagliotti G, Rosell R, Oliff I, Reeves JA, Wolf MK, Krebs AD, Averbuch SD, Ochs JS, Grous J, Fandi A, Johnson DH (2004a) Gefitinib in combination with paclitaxel and carboplatin in advanced non-small-cell lung cancer: a phase III trial - INTACT 2. J Clin Oncol 22: 785-794

Herbst RS, Johnson DH, Mininberg E, Carbone DP, Henderson T, Kim ES, Blumenschein Jr G, Lee JJ, Liu DD, Truong MT, Hong WK, Tran H, Tsao A, Xie D, Ramies DA, Mass R, Seshagiri S, Eberhard DA, Kelley SK, Sandler A (2005) Phase I/II trial evaluating the anti-vascular endothelial growth factor monoclonal antibody bevacizumab in combination with the HER-1/epidermal growth factor receptor tyrosine kinase inhibitor erlotinib for patients with recurrent non-small-cell lung cancer. J Clin Oncol 23: $2544-2555$

Herbst RS, Prager D, Hermann R, Miller V, Fehrenbacher L, hoffman P (2004b) TRIBUTE - a phase III trial of erlotinib CCl (OSI-774) compared with carboplatin and paclitaxel (CP) chemotherapy in advanced non- small cell lung cancer (NSCLC). Proc Am Soc Clin Oncol 23: (abstract 7011)

Heymach JV, Dong R-P, Dimery I, Wheeler C, Fidias P, Lu C, Johnson B, Herbst R (2004) ZD6474, a novel antiangiogenic agent, in combination with docetaxel in patients with NSCLC: Results of the run-in phase of a two-part, randomized phase II study. Proc Am Soc Clin Oncol 23: (abstract 3051)

Hurwitz H, Fehrenbacher L, Novotny W, Cartwright T, Hainsworth J, Heim W, Berlin J, Baron A, Griffing S, Holmgren E, Ferrara N, Fyfe G, Rogers B, Ross R, Kabbinavar F (2004) Bevacizumab plus irinotecan, fluorouracil, and leucovorin for metastatic colorectal cancer. N Engl J Med 350: 2335 - 2342

Hurwitz H, Holden SN, Eckhardt SG, Rosenthal M, de Boer R, Rischin D, Green M, Basser R (2002) Clinical evaluation of ZD6474, an orally active inhibitor of VEGF signaling, in patients with solid tumors. Proc Am Soc Clin Oncol 21: (abstract 325)

Johnson B, Ma P, West H, Kerr R, Prager D, Sandler A, Herbst RS, Stewart DJ, Dimery I, Heymach JV (2005) Preliminary phase II safety evaluation of ZD6474, in combination with carboplatin and paclitaxel, as 1st-line treatment in patients with NSCLC. Proc Am Soc Clin Oncol 24: (abstract 7102)

Johnson DH, Fehrenbacher L, Novotny WF, Herbst RS, Nemunaitis JJ, Jablons DM, Langer CJ, DeVore III RF, Gaudreault J, Damico LA, Holmgren E, Kabbinavar F (2004) Randomized phase II trial comparing bevacizumab plus carboplatin and paclitaxel with carboplatin and paclitaxel alone in previously untreated locally advanced or metastatic non-small-cell lung cancer. J Clin Oncol 22: 2184-2191

Kerbel RS (2004) Antiangiogenic drugs and current strategies for the treatment of lung cancer. Semin Oncol 31: 54-60

Korn EL, Arbuck SG, Pluda JM, Simon R, Kaplan RS, Christian MC (2001) Clinical trial designs for cytostatic agents: are new approaches needed? J Clin Oncol 19: 265-272

Kovacs MJ, Reece DE, Marcellus D, Meyer R, Matthews S, Dong R-P, Eisenhauer EA (2004) A phase II study of ZD6474, a vascular endothelial growth factor receptor (VEGFR) and epidermal growth factor receptor (EGFR) tyrosine kinase inhibitor (TKI) in patients with relapsed multiple myeloma (MM). Blood 104(11 Suppl): abstract 3464

Lucchi M, Fontanini G, Mussi A, Vignati S, Ribechini A, Menconi GF, Bevilacqua G, Angeletti CA (1997) Tumor angiogenesis and biologic markers in resected stage I NSCLC. Eur J Cardiothorac Surg 12: 535 - 541

Lynch TJ, Bell DW, Sordella R, Gurubhagavatula S, Okimoto RA, Brannigan BW, Harris PL, Haserlat SM, Supko JG, Haluska FG, Louis DN, Christiani DC, Settleman J, Haber DA (2004) Activating mutations in the epidermal growth factor receptor underlying responsiveness of non-small-cell lung cancer to gefitinib. $N$ Engl J Med 350: 2129-2139

Macchiarini P, Fontanini G, Dulmet E, de MV, Chapelier AR, Cerrina J, Ladurie FL, Dartevelle PG (1994) Angiogenesis: an indicator of metastasis in non-small cell lung cancer invading the thoracic inlet. Ann Thorac Surg 57: 1534-1539

Macchiarini P, Fontanini G, Hardin MJ, Squartini F, Angeletti CA (1992) Relation of neovascularisation to metastasis of non-small-cell lung cancer. Lancet 340: $145-146$

Meert AP, Paesmans M, Martin B, Delmotte P, Berghmans T, Verdebout JM, Lafitte JJ, Mascaux C, Sculier JP (2002) The role of microvessel density on the survival of patients with lung cancer: a systematic review of the literature with meta-analysis. Br J Cancer 87: 694-701

Miller KD, Trigo JM, Stone A, Wheeler C, Barge A, Sledge GW, Baselga J (2004) A phase II trial of ZD6474, a vascular endothelial growth factor receptor-2 (VEGFR-2) and epidermal growth factor receptor (EGFR) tyrosine kinase inhibitor, in patients with previously treated metastatic breast cancer (MBC). Breast Cancer Res Treat 88(Suppl): abstract 6060

Paez JG, Janne PA, Lee JC, Tracy S, Greulich H, Gabriel S, Herman P, Kaye FJ, Lindeman N, Boggon TJ, Naoki K, Sasaki H, Fujii Y, Eck MJ, Sellers WR, Johnson BE, Meyerson M (2004) EGFR mutations in lung cancer: correlation with clinical response to gefitinib therapy. Science 304: 1497 1500

Pavlakovic H, Havers W, Schweigerer L (2001) Multiple angiogenesis stimulators in a single malignancy: implications for anti-angiogenic tumour therapy. Angiogenesis 4: 259-262

Relf M, LeJeune S, Scott PA, Fox S, Smith K, Leek R, Moghaddam A, Whitehouse R, Bicknell R, Harris AL (1997) Expression of the angiogenic factors vascular endothelial cell growth factor, acidic and basic fibroblast growth factor, tumor growth factor beta-1, platelet-derived endothelial 
cell growth factor, placenta growth factor, and pleiotrophin in human primary breast cancer and its relation to angiogenesis. Cancer Res 57: 963-969

Schiller JH, Harrington D, Belani CP, Langer C, Sandler A, Krook J, Zhu J, Johnson DH (2002) Comparison of four chemotherapy regimens for advanced non-small-cell lung cancer. $N$ Engl J Med 346: $92-98$

Shepherd FA, Dancey J, Ramlau R, Mattson K, Gralla R, O'Rourke M, Levitan N, Gressot L, Vincent M, Burkes R, Coughlin S, Kim Y, Berille J (2000) Prospective randomized trial of docetaxel versus best supportive care in patients with non-small-cell lung cancer previously treated with platinum-based chemotherapy. J Clin Oncol 18: 2095-2103

Shepherd FA, Pereira J, Ciuleanu TE, Tan EH, Hirsh V, Thongprasert S, Bezjak A, Tu D, Santabarbara P, Seymour L (2004) A randomized placebo-controlled trial of erlotinib in patients with advanced non-small cell lung cancer (NSCLC) following failure of 1st line or 2nd line chemotherapy. A National Cancer Institute of Canada Clinical Trials Group (NCIC CTG) trial. Proc Am Soc Clin Oncol 22: 7022

Simon RM, Steinberg SM, Hamilton M, Hildesheim A, Khleif S, Kwak LW, Mackall CL, Schlom J, Topalian SL, Berzofsky JA (2001) Clinical trial designs for the early clinical development of therapeutic cancer vaccines. J Clin Oncol 19: 1848 - 1854

Sweeney CJ, Miller KD, Sissons SE, Nozaki S, Heilman DK, Shen J, Sledge Jr GW (2001) The antiangiogenic property of docetaxel is synergistic with a recombinant humanized monoclonal antibody against vascular endothelial growth factor or 2-methoxyestradiol but antagonized by endothelial growth factors. Cancer Res 61: 3369-3372 